\title{
The Difficulties of Launching and Operating CCUS Projects - Evidence from China
}

\author{
Qing $\mathrm{GAO}^{1}$, Rong $\mathrm{KANG}^{1}$, Anders EKELAND ${ }^{2}$, Jaroslav KOVÁRNÍK ${ }^{3}$ \\ ${ }^{1}$ Northwest University, Xi'an, China \\ \{gaoqing, kangrong\}@nwu.edu.cn \\ ${ }^{2}$ Statistics Norway, Oslo, Norway \\ Anders.Ekelandessb.no \\ ${ }^{3}$ University of Hradec Králové, Hradec Králové, Czech Republic \\ jaroslav.kovarnik@uhk.cz
}

\begin{abstract}
Serious environmental problems have resulted in an intense search for technologies to reduce emissions of green gasses in order to stabilize the climate change. CCUS was first proposed by Massachusetts Institute of Technology in 1989 as a way of climate change mitigation [9]. Since then, research on CCUS technologies have been rapidly developing and the International Energy Agency (IEA) has pointed CCUS technology one of the key technologies if we are to limit the temperature increase to $2^{\circ} \mathrm{C}$ by 2050 [1] However, this technology have been initiated and developed in a complex environment; with micro, macro and meso level barriers entangled, resulting making it difficult to full implementation of CCUS. We are focusing on the difficulties faced by the implementation of CCUS projects in China, since understanding more the difficulties will lead to a more optimal policy portfolio in the future for developing such projects.
\end{abstract}

Keywords: CO2, CCUS Technology, CCUS Pilot Project, Difficulties.

\section{Introduction}

As the world's largest $\mathrm{CO} 2$ emitter, China is facing serious tasks of decarburizing its economic growth. Meanwhile, the emission of non- $\mathrm{CO} 2$ greenhouse gases should not be neglected, which is crucial to the realization of the temperature control objective [4]. Since the $11^{\text {th }}$ Five-year Plan (2006-2010) began, the Chinese government has made unprecedented efforts to transform economic the growth model to make it more sustainable, and has moved to a low-carbon growth path. Until the Chinese $13^{\text {th }}$ Fiveyear Plan (2016-2020), the Chinese government announced that it would reduce carbon intensity by $18 \%$ from 2015 levels, and increase non-fossil fuel share of the primary energy mix to $18 \%$ by 2020 . China also announced that it will try to effectively control carbon emissions from key industries such as power, steel, building materials and chemical industry, and promote low-carbon development in industries, energy, construction of architecture, transportation and other key areas. China will also support and optimize the development regions to first of all achieve 
the peak of carbon emissions; further implementing various low-carbon pilot projects to build nearly zero carbon emission areas, pilot projects, including projects controlling non-carbon dioxide greenhouse gas emissions. In terms of achievement, by 2014, first of all China's carbon intensity decreased by $33.8 \%$ from the 2005 level; secondly, the share of non-fossil fuels in primary energy consumption reached $11.2 \%$; and finally, installed renewable power generation capacity reached about 425 Gigawatt (GW). However, to meet the further targets set by the government in the $13^{\text {th }}$ Five-year Plan (2016-2020), a total energy consumption cap is set at 5 billion tons of standard coal equivalent, requiring any new coal-fired power plants being "ultra-low emissions" and replacing coal in non-power sectors either with electricity or natural gas.

CCUS technologies can become crucial in climate change in the world, especially in big emission countries such as China, USA and India. The Fifth Assessment Report of the International Panel on Climate Change concluded that the costs of decarburization and long-term achievement of limiting global warming to two degrees centigrade without the deployment of CCUS will increase decarburization costs by more than 138\%. So far, fossil fuels in China have contributed $85 \%$ of the basic energy supply, of which coal contributes $70 \%$ of the basic energy supply, and electricity, heat and industrial sectors are dominated by coal. $\mathrm{CO} 2$ emissions from electricity generation and heating are account for 50\% of China's $\mathrm{CO} 2$ emissions, while other industries account for $30 \%$ of the rest. The IEA have forecasted that power plants of 430GW capacities need to install CCUS devices by 2040, where $60 \%$ of them are coal-fired power plants; moreover, $75 \%$ of coal-fired power plants all over the world that need to install CCUS devices are in China. Even as non-fossil fuels and low-carbon energy are deployed rapidly and on a large scale, coal will continue to be a major source of energy for future economic growth in China. Carbon emissions from the using of fossil fuels are unlikely to be effectively constrained by other existing mitigation technologies, so CCUS is the technology closest to becoming commercially viable that has the potential of cutting $\mathrm{CO} 2$ emissions by $90 \%$ or more frrom large-scale fossil-fuel industries and power plants.

\section{The Profile of CCUS in China}

\subsection{The Basic Information about the CCUS Pilot Project in China}

China has carried out CCUS related research and development and pilot built a number of CCUS projects. In capture technology, China has tested a variety of carbon capture technologies and is able to design and build a 1 million-ton CCUS device. There has been several smaller post-combustion CCUS installations with a capacity ranging from 3,000 tons to 120,000 ton.

By 2016, China is operating a total of 13 CCUS pilot projects, funded almost entirely by state-owned enterprises. The last of the pilot projects listed in Table 1 below were launched in 2013, clearly, indicating that the deployment of CCUS pilot 
projects has come to a complete halt. The detailed information is in the following Table 1.

Table 1. CCUS Pilot Projects in China

\begin{tabular}{|c|c|c|c|}
\hline & Name of Project & Starting Date & $\begin{array}{l}\text { Status in } 2016 \\
\text { (tons per year) }\end{array}$ \\
\hline 1 & Research and pilot of CO2 EOR in CNPC Jilin Oilfield & 2007 & 280,000 \\
\hline 2 & Pilot research in Sinopec Shandong Shengli Oilfield & 2010 & 40,000 \\
\hline 3 & $\begin{array}{l}\text { CCS pilot project in salty water layer of China } \\
\text { Shenhua CTL }\end{array}$ & 2011 & 100,000 \\
\hline 4 & CO2 EOR project of Sinopec in Zhongyuan Oilfield & 2008 & 100,000 \\
\hline 5 & $\mathrm{CO} 2$ enhanced coal bed gas mining project of CUCBM & 2010 & 1,000 \\
\hline 6 & $\begin{array}{l}\text { China Power Investment Shuang Huai power plant CCS } \\
\text { pilot project in Chongqing }\end{array}$ & 2010 & 10,000 \\
\hline 7 & $\begin{array}{l}\text { Clean coal power systems research facilities in } \\
\text { Lianyungang }\end{array}$ & 2011 & 30,000 \\
\hline 8 & $\begin{array}{l}\text { HUST research and pilot of } 35 \mathrm{MWt} \text { of oxygen-enriched } \\
\text { combustion technology }\end{array}$ & 2011 & 100,000 \\
\hline 9 & State Grid thermal power plant in Tianjin Beitang & 2012 & 20,000 \\
\hline 10 & China Huaneng Group Gaobeidian & 2008 & 3,000 \\
\hline 11 & China Huaneng Group power plant in Shidongkou & 2009 & 120,000 \\
\hline 12 & China Huaneng Group IGCC in Tianjin & $\begin{array}{l}\text { The capture } \\
\text { is finished, } \\
\text { the storage is } \\
\text { delayed }\end{array}$ & 100,000 \\
\hline 13 & Yanchang Group CCUS pilot project & 2013 & 50,000 \\
\hline
\end{tabular}

\subsection{The R\&D Investments of CCUS Technologies}

In China the government is the driving force behind CCUS, when it comes to reseach and development of CCUS; the government scientific research institutes and universities are the major contributors to participate in this field. Comparatively speaking, there are more funds for basic research, provided by the Ministry of Science and Technology, the Chinese Fund Committee, and through the financial aid of nearly 40 projects from the National Basic Research Plan, the National High Technology Development Plan, the National Science and Technology Support Plan, and so on. The funding is mainly for basic research, but also to certain degree covers technology development, and pilot projects, covering carbon capture, storage, transportation and utilization, as well as the whole process operation. However, it is clear that China domestic CCUS-related projects mainly focus on basic research, and that the CCUS pilot project funding and subsidies are insufficient for such projects to be commercially viable, since capital and running costs are too high. 


\section{The Difficulties of CCUS Pilot Projects}

The main difficulties in the implementation of the CCUS pilot project are as follows: high technology cost, lack of commercial viability, potential environmental risk, insufficient fund support, lack of policy and regulations, and so on.

\subsection{Costs and Benefits}

For such project is necessary high initial investment. Firstly, the cost of research for large CCUS pilot project is much bigger than for other infrastructure projects. This is due to the complexity of the project and the need for lot of expensive geological research related to finding a secure, long-term leak-free storage location. Secondly, the preparation of feasibility studies is also longer. Finally, a large amount of initial investments to purchase fixed equipment, the upfront investment of project is too high. Given that the lack of finance and capital support and with the high uncertainty of control and the low oil price market environment, the risk of investment for the commercial viability is higher, so the developers are unwilling to carry out the cost feasibility evaluation, even the Prophase project cost and the design research.

Second problem are higher operation costs. High cost, especially the high cost of capture, hinders the development of CCUS project. For example, the use of CCUS technology in power plants consumes more than $25 \%$ of energy than ordinary power plants, so investing in CCUS technology is an undoubted high-risk investment for business investors [8]. In addition comes environmental monitoring transportation of $\mathrm{CO} 2$ to the location of storage and so on.

\subsection{Lack of Demand for the Captured $\mathrm{CO} 2$}

The basic problem for CCUS is the lack of demand for the $\mathrm{CO} 2$ captured. Up to now it has only been when storage of $\mathrm{CO} 2$ has been connected to using $\mathrm{CO} 2$ as a way to get more oil out of an existing oil field, enhanced oil recovery (EOR) that CCS has been commercially viable. The "classic" example is the Sleipner field in the North Sea. Sleipner started in 1996 and is still operating. In the case of Sleipner the commercial viability was also dependent on a $\mathrm{CO} 2$ tax of approximately 50 USD implemented in 1991 by the Norwegian government. In Europe the first wave of pilot projects from 2007 to 2010 could calculate a price of CO2 emissions of 20-30 Euro per ton from the EU emission trading system (ETS). But as the $\mathrm{CO} 2$ price started to fall to 10-15 Euro (2009-2011) and the fell to 5-6 Euro per ton and stabilized at that low level none of the projects planned by two EU CCS programs were realized as of April 2013.This coincides in time with the halt in the Chinese pilot projects, but there need not be any direct or indirect causation between the EU and Chinese policy. But these project were not EOR projects. With the dramatic fall of the price of oil from August 2014 to January 2015 and no recovery in sight, even EOR projects are not profitable without some subsidies. When it comes to projects using the $\mathrm{CO} 2$ captured - not just storing it - so far no commercial viable large products have been found that have a potential demand on the enormous scale needed, so scientific discoveries 
leading to "disruptive" technologies are needed. Something like cheap, artificial photosynthesis.

\subsection{Difficulties to Assess the Economic Benefits of CCUS Pilot Projects}

The main contribution of the CCUS project is to ensure a good living environment for human beings by directly slowing climate change or stabilizing climate. The value, the economic cost of global warming climate change is difficult to measure. This problem is highlighted in the exchange of views between such well-known economists as Martin Weitzman and William Nordhaus about Weitzman's so-called "Dismal Theorem". The "Dismal Theorem" states that in a situation where there is radical uncertainty, i.e. we do not know the probability of very catastrophic consequences of global warming. This can be modelled as models with "fat tails". Which in a Cost-Benefit framework points directly to setting a "precautionary price" on $\mathrm{CO} 2$. How to set that price, the level, and rate of increase etc. is beyond the scope of this article to discuss, but it is clear that without $\mathrm{CO} 2$ getting a price substantially higher than the current price than the EU ETS CCUS will not "take off". Without such an "internalization" into the costs the inputs the enterprise uses, the enterprise will lack the economic incentive of installing CCUS and as a consequence incentives to support R\&D on CCUS, support pilot project installation etc. For example: in recent years along with the global warming and the increase of human social and economic activities, the permafrost in the middle and east of Qinghai Plateau, which is in the transition zone of permafrost to flake succession, is significantly degraded [7]. The popularization and use of CCUS can mitigate climate change and even stabilize climate change, thus protecting the permafrost and ecological environment can produce economic benefits, but the economic benefits are difficult to measure. Just to take one example of very many.

\subsection{Policies, laws and regulations of CCUS are not in place}

Since 2006, both Chinese central government and local governments have issued a series of policies and regulations to promote the development of CCUS pilot projects, which include also The Special Action on Climate Change in China. In December 2016, China National Development and Reform Commission and the State Bureau of Energy jointly issued The Thirteenth-Five Plan of Coal Industry Development. The document contains a series of policies and regulations showing the determination of the Chinese government to develop and promote CCUS technologies. However, China currently lacks relevant laws and regulations for site selection, construction, operation, environmental risk assessment, and monitoring after the closure of the storage site. Even in more developed United States, when it comes to CCUS, there is still a lack of a complete set of laws and regulations that can be used to clarify jurisdiction of CCUS [1]. For example, to determine the jurisdiction of storage of $\mathrm{CO} 2$, it is important to clarify the nature of the storage firstly. Should it be defined as an industrial product, or as a pollutant; if it is defined as an industrial product, the injection project is managed by the existing law of oil and gas; if it is a pollutant, the 
right of management of $\mathrm{CO} 2$ belongs to the scope of environmental regulation. In addition, because of the late development of China's 7 pilot markets for carbon trading, the trading system is far from perfect to put it mildly. There are still large prices fluctuations, high risk, which restrict the proper function of a market price. There is also insufficient liquidity, limited transaction volume in some regions, and so on. Given the current carbon price, companies lack enough incentives to upgrade their emissions-reduction technologies [6]. The key to the establishment of the CCUS legislation and supervision system in China is solving the problem of nature of land and underground rights of $\mathrm{CO} 2$ guaranteeing health safety and environment, transferring and protecting intellectual property rights, a well-functioning project approval system and the economic and political incentive system, and so on [3].

\subsection{Low Level of Openness and Public Awareness of Project Information}

In China, the data of many CCUS project are not accessible for neither the general public nor universities. Scientists cannot conduct the detailed economic and political research needed for learning from the experiences so far and that is an obstacle to the wider up-take of CCUS technology.

At present, CCUS being an emerging technology in the early development stage, the general public knows only the greenhouse effect and its long-term hazards, but there is little knowledge of the deployment of CCUS technology. The lack of knowledge about CCUS in the public will create barriers to the promotion and application of CCUS technologies [2].

\subsection{Problems with the Immature Core Technology}

In the capture, due to the low technology maturity of capturing before combustion, capturing after combustion and oxygen-enriched burning, it is difficult to determine which technology should be used in large scale operation of CCUS in the future; it is also difficult to determine applicable range, energy consumption, and cost of these technologies, while they have usually different features. Transportation mainly relies on either road transport mainly, railway; pipeline, or ship transportation technology, which also need to be developed [10]. Regarding storage, there is no comprehensive geological survey, no clear storage potential assessment and site selection criteria. There is also a lack of site survey technology and safety monitoring technology. The construction and operation of CCUS involves technology transfer and application, economic benefits, environmental impact, emission reduction benefits and other aspects, and China needs to establish a series of CCUS technology implementation and monitoring standards to ensure the project implementation and technical feasibility in storage, safety and effectiveness [5]. 


\subsection{Inadequate Financial Support}

For early pilot projects, additional financial support is needed to build a CCUS pilot project with commercial viability. The support could also take the form of a price (tax) on carbon using the tax-revenues to support CCUS. In China, the CCUS project investment can be summed up in two parts. First one is key project which is supported by the national Government's Scientific Research Fund, where second one is the investment of State-owned enterprises as the mainstay of the project. If the economic contribution of the CCUS pilot project levels is not accepted by government or by enterprise in the long-run, the sustained and reasonable amount of financial investment will not be guaranteed. Before 2020, the IEA expects 100 CCUS projects to be developed with an additional cost of $\$ 54$ billion, where China and India may develop 21 projects with an additional cost of $\$ 7.6$ billion. Due to the imperfect incentive policy and uncertain business prospects, the current CCUS pilot project funds in China mainly originate from the plan of national science and technology, the self-financing of the central enterprises, complemented by the financing from the international cooperation projects. So far, the venture capital has been unwilling to invest in CCUS and the CDM financing has also practically stopped completely. All these factors sum up to making the investment difficult consequently to meet the require uptake of CCUS needed for meeting the emission reductions necessary to stay below 2 degrees of global warming of development of CCUS [10].

\subsection{Significant Potential Negative Environmental Influence}

The large-scale application of CCUS technology has a potential negative influence on environment, personal health, and safety. The capture process demands an increase of energy consumption and the consequent increase of $\mathrm{NO}_{\mathrm{x}}, \mathrm{SO}_{\mathrm{x}}$, and other pollutant emissions. The potential impact of transportation like pipelines on natural scenery. The problem with storage is mainly resulted from the leakage of $\mathrm{CO} 2$, which can lead to human poisoning, to ocean acidification, to soil pollution, to groundwater pollution, and it can even induced earthquakes [7]. Both geological and marine storage of $\mathrm{CO} 2$ have a risk of leakage, and it definitely needs to be taken into consideration. If the percentage of $\mathrm{CO} 2$ is over $8 \%$, it can quickly endanger human health and life. In 2006, the IPCC developed The Framework of CO2 Geological Storage Risk Assessment and Management to guide and resolve the problem of $\mathrm{CO} 2$ leakage. The results show that the safe $\mathrm{CO} 2$ storage period can be up to millions of years, as long as the suitable storage sites are properly selected, designed, and managed [8]. Even if the probability of $\mathrm{CO} 2$ leakage is very low, the leak prevention should be done in every part of the storage process. Monitoring is an effective tool for preventing the chance of risks, but China has not established a complete and effective environmental monitoring system yet. The questions how effectively monitor CCUS projects and how long it takes to recover from the leakage will be serious challenge for the Chinese Government and big government enterprises. 


\section{Conclusions}

To sum up, the CCUS projects, although IEA and other international organizations have emphasized its positive role in decreasing carbon emission and helping protecting environment, have to face serious problems. The comparison study between CCUS and other non-fossil energy technology must be done to locate a more effective and more efficient portfolio of energy consumption.

\section{References}

1. Carbon Capture Use and Storage, https://www.c2es.org/technology/factsheet/CCS, last accessed 2017/10/25.

2. Cheng, Ch.: Analysis on Status of CCS Technique and Its Prospect in China. Journal of Jianghan Petroleum University of Staff and Workers 23(2), 4 (2010).

3. Huang, Y., Zhao, D.: Research on Policy and Legislation of Carbon Capture, Utilization, and Storage in China. Chinese Academy of Sciences 1(1), 9 (2016).

4. International Energy Agency: World Energy Outlook 2016. $1^{\text {st }}$ ed. International Energy Agency, France (2016).

5. Li, H.: China's Development Potential and Latest Actions on CCS. China Coal 36(1), 5 (2010), DOI: 10.3969/j.issn.1006-530X.2010.01.004.

6. Lin, Y., Xian, Z.: Chinese companies' Awareness and Perceptions of the Emissions Trading Scheme (ETS): Evidence from a National Survey in China. Energy Policy 98(1), 254-265 (2016), DOI: 10.1016/j.enpol.2016.08.039.

7. Luo, D., Lin, L., He, R., Yang, S., Chang, X.: Degradation of Permafrost and ColdEnvironments on the Interior and Eastern Qinghai Plateau. Journal of Glaciology and Geocryology 34(3), 538-546 (2012).

8. Sha, L.: Present Situation and Problem of CCS Technology Development in China. Shanxi Chemical Industry, 1(4), 4 (2015).

9. Wenjia, G.M.C.: CCS's Development Status and Related Policies in the World. China Energy 35(3), 4 (2013).

10. Zhu, F.: CCS in China: Status Quo, Prospects and Obstacles. Energy Technology and Economics, 23(1), 4 (2011). 